\title{
Challenges Faced By Women Orphans' Caregivers: A Qualitative Study
}

\author{
Sundus Yousuf \\ Institute of Clinical Psychology \\ University of Karachi \\ Bushra Khan \\ Department of Psychology \\ University of Karachi
}

\begin{abstract}
Wellbeing of an orphan caregiver affects the child-rearing practice, which in turn could affect the growth and development of the orphaned child. Challenges faced by women orphan caregivers make caring a more extraneous task. A qualitative study was designed, to investigate the challenges faced by women orphan caregivers. Data was collected from SOS children village, an internationally recognized orphanage located in Karachi, Pakistan. An open ended interview was conducted with 17 women orphan caregivers employed at the organization through interview schedule. Various themes were identified. Two major themes indicating challenges were identified; professional or organizational level and personal level that were further divided in sub themes and analyzed. Results indicated that caregivers themselves were abandoned and suffered from psychological disturbances and lacked in awareness of effective coping skills. Orphan caregivers faced distress due to inability to effectively handle hectic routine at the orphanage, low salary, and lack of knowledge and skill to address diverse needs of all children. Overall, caring for orphans is a challenging job and it is recommended that orphan caregivers are provided with professional support to cope with psychological issues; and training on caregiving knowledge and skills to effectively handle children with diverse needs. This could eventually help in improving wellbeing of the caregivers and enhancing overall development of the orphans.
\end{abstract}

Keywords: Women Orphans' Caregivers, Challenges, Qualitative Study, Pakistan.

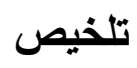

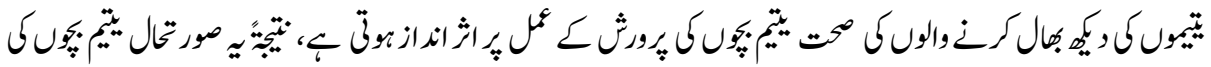

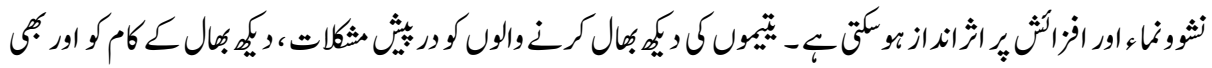

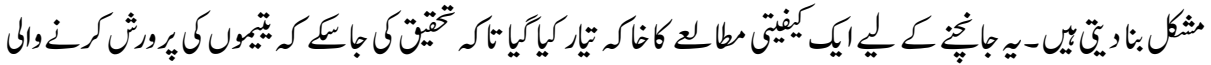

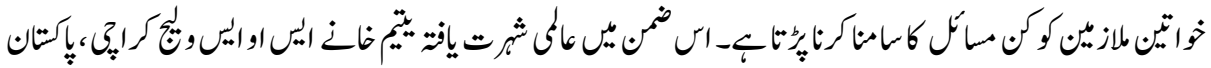

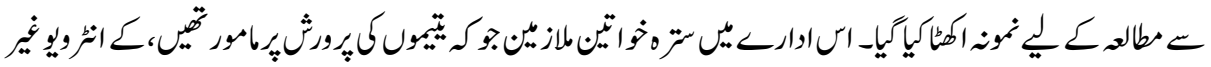




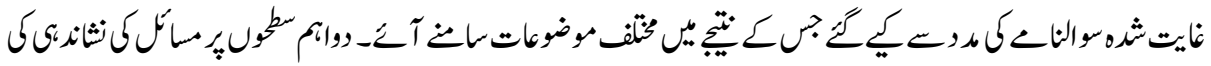

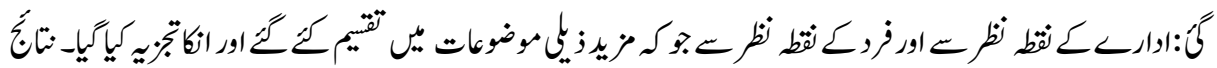

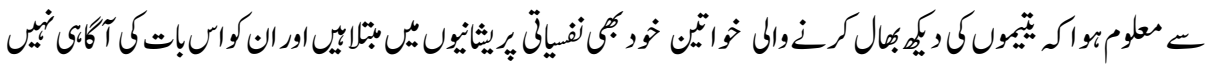

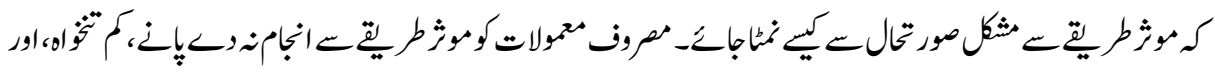

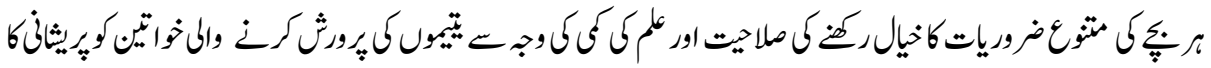

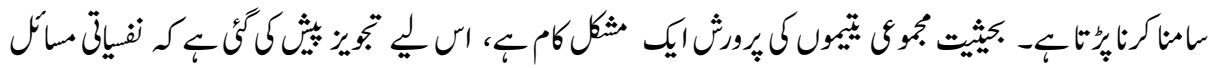

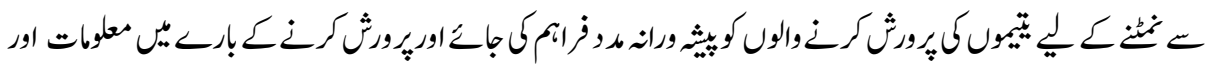

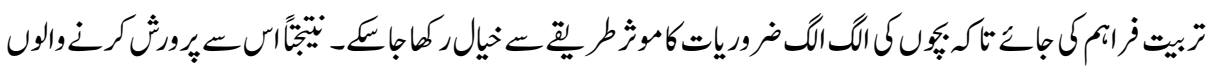

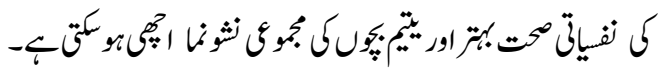

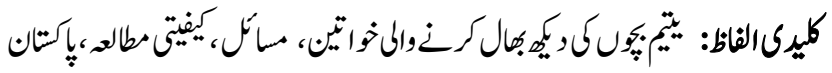

\section{Introduction}

"Love cures people, both the one who give it and ones who receive it”. Karl A. Menninger.

Caregiving of orphans is an extraneous job (Hlabyago \& Ogunbanjo, 2009). Therefore, the well-being of the caregiver is essential and has a huge impact on the upbringing of the child. A substantial amount of research is done on the well-being of the orphans. (Juffer \& Series, 2008; Zhou, 2012; Zhao et al., 2010; Killian \& Durrheim, 2008; Radcliff, Racine, Huber \& Whitaker, 2012; Makame, Ani \& Grantham-McGregor, 2002). Nonetheless, few researches are done on caregiver's psychological wellbeing (Bachman et al., 2008).

Natural disasters, acts of terrorism, migrations, fatal diseases such as HIV AIDS and other afflictions of life bring with itself many miseries and hardships to handle. To care for the orphans several orphanages are established under governmental and nongovernmental organizations. According to Joint United Nations Programme on HIV/AIDS (2007). An orphan is defined as a child under age 18 who has lost at least one parent (maternal orphans, paternal orphans) or both the parents (double orphans). Beside this definition, there is also a term of 'Social Orphan' which is used to refer a child, whose parents are alive but do not take the responsibility of providing the parental care (Dillon, 2009). The reasons for widespread social orphan hood are social, cultural, economic and often a combination of these factors. Children often become social orphans due to alcoholism, neglect and abuse (Firsava, 2012). Also, often legal or social barriers separate the child from parental love and sometimes family conflicts; divorce, violence 
and abuse leave behind the children to live apart from the safe and protected environment of home (Excluded children, 2010). The orphanages usually take care for both, 'orphans' and 'social orphans'. Although the innocent child is not responsible for being orphan, orphan-hood brings with itself many misfortunes. The society looks down upon the orphans and feels no guilt in snatching their basic rights because they lack parental support (Abebe, 2009). It is, therefore, the duty of state to provide shelter and support to such deprived children. Often this task is fulfilled by non-governmental organizations with the help of corporate sector, government and wealthy philanthropists of the society.

The best care for deprived and misfortunate orphans can be guaranteed only when physical, psychological, social and emotional health care is monitored by the organization in which they are living in (Juffer \& Series, 2008). Community based home groups provide the best psychosocial care for the orphans (Hong, et al., 2011). Physical health encompasses proper nutritional daily diet, medical checkups, resources of proper sanitary system and physical exercising and gaming opportunities. Social wellbeing comes from intact social setup that helps children shield from social stigma. Emotional health is ensured only when the child knows that he is being loved and there is a place on earth where he/ she can act independently without any apprehension. Psychological fitness of the orphan is the sum of all above mentioned factors. Moreover, the psychological wellbeing of the child is also associated with the mental health of the care giver.

\section{Review of Literature}

Wellbeing of caregivers plays an important role in child development. Mentally disturbed care providers possess potential of negative impacts on the child-rearing practice. They may fail to understand child's cries, react in hostile manner, and practice inconsistent disciplinary methods, unable to understand the emotional state of the child. This inability could affect the child's growth and mental health. Several outcomes of studies indicate a predictive relationship between better child's developmental status and social and mental skills in later life with caregiver's responsiveness and secure attachment styles. (Avierzer, Sagi, Resnick, \& Gini, 2002; Bradley, Corwyn, Burchinal, McAdoo, \& Coll, 2001; Landry, Smith, Swank, \& Miller-Loncar, 2000; Hellenthal, 2006).

Studies conducted on mothers as caregivers revealed that maternal anxiety and depression is related with increased chance of anxiety, depression, attention deficit, and oppositional defiant disorders among 3 year old children (Meadows, Mc Lanahan, \& Brooks-Gunn, 2007). Several research results indicate that marital discord and maternal stress has a significant impact on child's behavior and adjustment. Children who belong to violent families have more internalizing behavior problems, are more aggressive and bad tempered (Holden \& Ritchie, 1991). Mother's stress may result as 'emotionally unavailable mothers' (Dunn, 1988), which causes low adrenocortical stress reactivity in 
children (Sturge-Apple, Davies, Cicchetti \& Manning, 2012). Moreover, maternal stress may manifest 'diminished mothering' (Walker, 1979). A study examined the childrearing patterns in depressed, abusive, and normal mothers revealed that depressed and abusive mothers are found to be inconsistent, hostile and protective and utilize guilt inducing methods. Abusive mothers synchronize it with harsh authoritarian practices. (Susman et al., 1985; Rakow, et al., 2011). Moreover, depressed mother's children lacks in social, psychological, and cognitive domains. They themselves are at risk for depression and other psychiatric illness such as conduct disorder (Burke, 2003). There is generally a dearth of studies showing relationship of behavior of orphan caregivers in institution and the orphans' overall wellbeing. However one study where grandmothers raising their orphaned grandchildren reported elevated level of stress in grandmothers as compared to biological mothers. Caregivers' experienced stress was linked to advanced age and extensive, new adoptive roles now occupied by grandmothers (Oburu, 2005).

Worldwide comparatively more researches are done on the well-being of the orphan child as compared to orphan caregivers. Most reported researches are on the orphans due to AIDS; for example in Malawi (Chirwa, 2002), Ethiopia (Abebe \& Aase, 2013), Zimbabve (Howard, et. al., 2006), Cape Town (Cluver \& Gardner, 2007), Botswana (Miller, et. al., 2005). These researches outnumber for the Sub-Saharan countries, as prevalence of HIV aids is most amongst these countries. Very few studies have been conducted (Hlabyago \& Ogunbanjo, 2009; Guqa, 2012; Thielman, Ostermann, Whetten, Whetten, O’Donnell, \& Positive Outcomes for Orphans (POFO) Research Team, 2012), especially in Pakistan. A study was conducted to investigate behavioral problems of children living in orphanages deduced that orphan children are at greater risk for behavioral and conduct problems if the caregiver is suffering from depression or anxiety. Such caregivers direct children with higher number of commands and criticism, who in turn respond in a non-compliant and deviant behaviour (Lassi, Mehmud \& Syed, 2010).

Considering the vital role of orphans' caregivers in the children holistic development and dearth of a detailed study to know the perspective of orphans' caregivers, the aim of the current qualitative study was to explore experiences and challenges of women working as caregivers of orphans in an orphanage.

\section{Methodology}

Study was conducted at the internationally recognized orphanage SOS village (a registered non-governmental organization) located in Karachi, Pakistan. This orphanage makes an effort to fulfil physical, emotional, social and academic needs of orphans. It provides safe and spacious physical and social environment and orphans are taken care by female caregivers who provide care to them on 24/7 basis. The orphanage has been divided into 4 sections called as Neighbourhood (Mohallas). Each neighbourhood has 4 
homes which is taken care by one caregiver. The orphanage has 18 caregivers where, 16 caregivers provide care to orphans while 2 remain standby in case any need for orphan care arises. Besides salary, organization provides caregivers with food and shelter.

\section{Participants}

17 female orphan caregivers, employees of SOS village Karachi, were interviewed individually. Participants were approached through purposive sampling technique. Their age ranged from 23 to 51 years (mean=35). Most of them were divorced $(\mathrm{N}=10)$ while others were either widowed $(\mathrm{N}=3)$ or unmarried $(\mathrm{N}=3)$. These women resided in SOS, and other than a salary they were provided with the food, shelter, clothing, and permission for their own child to reside with them (out of 17, 5 caregivers had children who lived with them in the institution).

\section{Measures}

Besides socio-demographic information that included age, marital status, number of children, salary and benefits. An open-ended interview schedule was developed in accordance with the purpose of this research (please refer to the appendix). The interview schedule was reviewed by the psychologists and piloted on two caregivers working in another similar orphanage.

\section{Procedure}

The purpose, objective, methodology and interview schedule was discussed in detail with Director of SOS orphanage and consent to conduct the study was taken. Verbal informed consent was taken from the caregivers before conducting the interviews. Moreover permission for audio recording interview was also taken. 12 caregivers allowed recording the interview while for rest of interviews written notes were taken. Each interview lasted for 60 to 90 minutes. Essential probing was done when the caregivers were not able to define their problems adequately and when they were reluctant to open up and discuss their challenges.

\section{Analysis}

Interviews were transcribed and written notes were rechecked for completion. Authors discussed and analyzed all interviews in detail. Themes were identified and further classified into major and sub-themes. 


\section{Results}

Almost all caregivers belonged to broken homes; have passed through some trauma in the form of physical or sexual abuse, faced death of some significant figure on whom she was dependent economically, socially and emotionally.

\section{Life History of Caregivers}

Around half of the women caregivers had a history of unsuccessful marriage. And they were also abandoned by their families in specific and the society in general. Few of them had long-suffered physical abuse from their husbands and were tyrannized by their husbands and often mother-in-laws too. One woman reported, "I lived and tolerated the loose character and brutality of my husband for 7 years". After this long period of oppression she decided to leave him. Her two twin daughters are still with father and her case is under trial in court. One woman did court marriage with a man who was already married. Afterwards he showed no concern for her and the child, so she decided to leave. One lady stayed for 5 years with a man who was extremely suspicious, brutal to the extent that once he blew up her head by hitting her hard. In another story, husband didn't care for the wife and never showed interest in her rather beat and accused her. One woman told, "After 5 months of marriage my husband said to me now I can no longer afford you" and gave divorce. One woman was infertile and due to this her husband married her cousin without her consent. Another woman was rejected by the man after 'Nikah' because according to him she was not beautiful. She was also not supported by his father and had worst ties with step-mother. Three women did not have such history. Rather their husbands died their natural death. And they found SOS village a safe place to be employed and support themselves and their child to continue their livelihood. One woman was herself an orphan child, raised in the village. Now she is working as an employee there. She said, "My father was a great man. After his death no one supported us and I still feel very deprived." According to another woman caregiver's history, successive traumatic events in her life left her unmarried and she works there in order to support herself and her family. One woman told that her husband was a schizophrenic patient. She was not told this before marriage. She expressed, "I tolerated him and helped in his treatment, but after several years, I and my brothers became hopeless with his recovery and I decided to leave him". Another woman was forced to married to an old man who already had 7 children. Her husband was good for nothing. All her life she struggled hard, did jobs and cared for her and her husband's children. After arranging marriages of all 7 children, when she was left alone she found SOS a safe place to live in. Her words were, "I was scattered; SOS saved me".

\section{Reason of Joining Orphanage as Caregivers}

Most of the women caregivers approached the organization through some relative or friend. Only two caregivers got to know about the organization through newspaper 
advertisement. Some were shifted from other regional SOS villages. Caregivers reported that they joined SOS to get a secure job along with the protective environment, food and shelter.

The major reason is the safety that the organization ensured in a safe and healthy environment; "The most important thing for a woman is security and respect" reported most of the caregivers. Also the lenient policy of the organization which not only allowed caregivers to keep their biological children with them but also provide them all facilities that entertain other children.

\section{Challenges Faced by the Caregivers}

They reported number of challenges that they were facing while working in the orphanage. We have thematically divided them into two main categories as challenges at organizational and personal levels that included thematically linked sub categories.

\section{Professional and Organizational Level}

\section{A Hectic Routine}

Caregivers work 24 hours and seven days a week. It involves completion of lot of chores. A busy day starts in the morning. As narrated, "We have to prepare breakfast for all 10 children prepare them for school. When they are off to school we have to clean up the entire house, prepare lunch for the children. When they are home we provide them with lunch, help them complete their homework, teach them good manners, resolve their issues and then again prepare for them the dinner. All the day is busy and hectic. I get really tired". This hectic routine results in creating stress and sometimes distress amongst the caregivers.

\section{Diverse Needs of Children}

Caregivers reported that usually they found difficulty in managing challenging children, especially ones who were aggressive, non-responding or hyperactive. One mother said, "children are very hostile, aggressive and non-understandable...don't know how to better deal with them".

\section{Low Stipends}

With ever rising inflation in the country, caregivers demanded an increase in their salary packages, one caregiver said, "I'm worried about my salary. It's very less and not enough as compared to our work". Most of the caregivers were also worried about the continuity 
of their job as one caregiver reported, "We have no job security, we can be fired anytime". Most of the mothers lacked foresight and future planning for their lives.

\section{Personal Level}

\section{Reliving Traumatic Experiences}

Women caregivers reported that the hectic routine prove to be blessing in disguise. They tend to forget their traumas and thought less about themselves when they were busy in their tasks. However, when at night they got free from their work, they relived all the past memories and felt helpless and lonely. Some often experienced crying spells as well.

\section{Lack of Awareness of Effective Coping}

Investigating the coping strategies for dealing with their problems it was disclosed that most of the caregivers avoided thinking about their problems and engaged in different activities. One caregiver said that, "I read books or listen to songs." One caregiver said that, "I engage myself more with my orphan children." Five caregivers reported that they find their relaxation in the night prayers. They put all their grievances and complain in front of God. By this act they feel much relieved.

\section{Experiencing Psychological Issues}

Upon telling their life history 6 caregivers revealed that they had suffered through severe depression. Amongst them some also had taken medication for depression prescribed by the local general physician. Two caregivers informed that when they were passing through the trauma they had attempted suicide. In few caregivers, element of extreme fear still prevailed. For example, one caregiver said that "I fear that only if for one day I will leave the premises of SOS village, I will be killed." Another caregiver expressed, "I fear that all the traumas might come back." One caregiver with history of sexual abuse frequently cried at petty issues and she herself did not know the better way to soothe herself and cope with the feeling of disgust in her. Feeling of loneliness was also a common complain of most of the caregivers.

\section{Discussion}

Orphan care giving is a demanding task; and doing that job with challenges makes it more difficult. Our study brings out number of important themes that highlights the challenges women orphans' caregivers are facing; be it at professional or personal level that could influence the quality of work. 
Low income was found to be an important concern, especially when they compare with the amount of time and energy they invest. Provision of quality care to orphans is a necessary requirement for caring the vulnerable population in orphanage. Low salary may not only affect caregivers' level of motivation to provide quality caregiving services but may also cause movement of the employees to other organizations, causing a scarce of staff available to work in orphanages. According to the results of an experimental study, enhanced services and increased monthly stipends and imparting value and meaning in the workers can increase their retention rate in the job (Chamberlain, Moreland \& Reid, 1992).

Handling diverse needs of children require skilled and trained staff, especially when children have emotional or behaviour problems (Lassi, Mehmud \& Syed, 2010). Our findings showed that women orphan caregivers joined the organization because it provided them basic amenities and they lacked prior knowledge and skills required to work with children in orphanages, consequently they found challenging to deal with children with behaviour difficulties. Studies have been found that lack of sufficient skills in handling of orphans could lead to negative effects, for example a study carried out by The Nelson Mandela Children's Fund indicated that due to lack of parental guidance, orphaned children were at risk of developing delinquent and anti-social behaviors and could emerge as less productive member of the society (Schonteich, 2002). Moreover a study in China also revealed that illiterate caregivers were more likely to have delinquent children and emphasizes on the parenting skills of the caregivers (Sun, Li, Ji, Lin, \& Semaan, 2008). On the other hand provision of caregiving by trained orphan caregivers could lead to better physical and mental development among orphans (Groark, Muhamedrahimov, Palmov, Nikiforova, \& McCall, 2005).

Child care is a demanding task and performing it continuously could be exhausting. Joint United Nations program (UNAIDS 2008) highlighted that the physical and psychological effects of caregiving on female caregivers' health are not recognized as women usually disregard their own wellbeing and sanity, consequently it could lead to emotional stress. Our study also revealed that Women orphans' caregivers were expected to perform their duties without breaks that could help them rejuvenate. Although they reported that they try best to do their jobs as it helped them to temporarily forget their traumatic past, but continuous work could lead to emotional stress (UNAIDS 2008).

It was interesting to find that all caregivers had a history of personal trauma and most of them belonged to broken families, faced abuse and domestic violence, and some even suffered from psychological illnesses as well. It was reported that they still re-live those negative moments that affect them psychologically. In addition to that they tried to divert their painful emotional experiences by engaging in work or performing religious rituals and lacked strategies that could help them effectively cope with their emotional issues. 
Researches indicate that not only caregivers' poor health be it physical (Thielman, Ostermann, Whetten, Whetten, O'Donnell, the Positive Outcomes for Orphans (POFO) Research Team, 2012) or mental (Lassi, Mehmud \& Syed, 2010) influences the health and behaviour of children but it could also lead to poor quality of caregiving (Lovejoy, et. al., 2000; Lassi, Mehmud \& Syed, 2010). Provision of psychological counseling and guidance could help caregivers better cope with their problems.

Moreover, the women working as orphans' caregivers are themselves rejected by their family members and are deprived of the relationships they used to have. According to Relational-Cultural Theory, which was conceived after the work of Jean Baker Miller (1976) and is aligned with feminist movements in psychology, healthy relationships plays an important role in maintaining psychological wellbeing (Comstock, Hammer, Strentzsch, Cannon, Parsons, \& II, 2008). These caregivers regain their chance of involving themselves into growth-fostering relationships by taking care of orphans. Communicating and acknowledging their important contribution in orphans' lives could not only strengthen their bond with orphans but could also enhance their level of job satisfaction.

A good reputable and managed organization faces fewer problems. SOS village is one such example that rendered as a model facility for orphaned children (Lassi, Mehmud \& Syed, 2010). However, dealing with human lives and catering the issues of such a vulnerable population itself predict for many psychological, social and emotional issues. Unbiased exploration of problems and then pondering upon the best possible solutions can be a useful step towards moving one step forward. Because psychological health of orphans' caregivers and lack of emotional support could affect development of the child (Groark, McCall, \& Fish, 2011; Thielman, et.al, 2012).

Considering the current situations where many children are getting orphaned due to war, illness, disaster or death of parents or parental abandonment it was interesting to note that there is a dearth of literature that focuses on in-depth understanding of the challenges faced by the orphans' caregivers working in the orphanages. Most of the studies were done on orphans due to certain reason like HIV AIDS. Especially in Pakistan only one study reported the psychological status of caregivers (Lassi, Mehmud \& Syed, 2010) but its finding was based on the quantitative data. To best of our knowledge our study is the first to report a detailed account of women orphan caregivers' experiences and highlight their challenges in Pakistan.

\section{Conclusions}

Our study explored the experiences of women caregivers who were involved in providing care to orphans. This study highlights their various personal and organizational 
challenges that included their poor psychological well-being, lack of stress coping skills, lack to caregiving skills, and low salary with exhausting and demanding job. Our study emphasizes the importance of understanding and addressing the needs of women caregivers that could improve caregiving process and eventually could influence better all-round development of orphan children.

\section{Recommendations}

Following are the few recommendations based on the findings of our research:

- Caregivers' financial and administrative needs should be addressed because it could enhance their motivation and commitment to continue working as professional orphan caregivers.

- Training on care giving skills and handling children with difficulties need to be provided as it could improve quality of care giving.

- A series of mental health workshops could be arranged for the women caregivers that could include areas on stress management, time management and ways to enhance resilience.

- Individual counselling sessions should be provided to caregivers with the history of trauma. Also women with any psychiatric symptoms should be consulted the mental health experts.

\section{Acknowledgements}

We thank all the women orphan caregivers who participated in this study and shared their life experiences in detail. We appreciate the permission and facilitation provided by the director of SOS children's village, Karachi in the conduct of this study.

\section{References}

Abebe, T. (2009). Orphanhood, Poverty and the Care Dilemma: Review of Global Policy Trends, Social Work and Society, vol.7:1, pp.70-85.

Abebe, T. \& Aase, A. (2013). Children, AIDS and the Politics of Orphan Care in Ethiopia: The Extended Family Revisited. Social Science \& Medicine, vol.64:10, pp.2058-2069.

Avierzer, O., Sagi, A., Resnick, G. \& Gini, M. (2002). School Competence in Young Adolescence: Links to Early Attachment Relationships beyond Concurrent SelfPerceived Competence and Representations of Relationships. International Journal of Behavioral Development, vol.26:5, pp.397-409. 
Bachman, D., M., Beard, J., Cakwe, M., McCoy, K., Nkosi, B., Parikh, A. \& Simon, J. (2008). Vulnerability of Orphan Caregivers vs. Non-Orphan Caregivers in KwaZulu-Natal. Vulnerable Children and Youth Studies, vol.3:2, pp.102-111.

Bradley, R. H., Corwyn, R. F., Burchinal, M., McAdoo, H. P. \& Coll, C. G. (2001). The Home Environments of Children in the United States. Part II: Relations with Behavioral Development through Age Thirteen. Child Development, vol.72:6, pp.1868-1886.

Burke, L. (2003). The Impact of Maternal Depression on Familial Relationships. International Review of Psychiatry, vol.15:3, pp.243-255.

Chamberlain, P., Moreland, S. \& Reid, K. (1992). Enhanced Services and Stipend for Caregiver Parents: Effects on Retention Rate and Outcome of Children. Child Welfare, vol.71:5, pp.387-401.

Chirwa, W.C. (2002). Social Exclusion and Inclusion: Challenges to Orphan Care in Malawi. Nordic Journal of African Studies, vol.11:1, pp.93-11.

Cluver, L. \& Gardner, F. (2007). Risk and Protective Factors for Psychological WellBeing of Children Orphaned by AIDS in Cape Town: A Qualitative Study of Children and Caregivers' Perspectives. AIDS Care: Psychological and SocioMedical Aspects of AIDS/HIV, vol.19:3, pp.318-325.

Comstock, D. L., Hammer, T. R., Strentzsch, J., Cannon, K., Parsons, J. \& II, G. S. (2008), Relational-Cultural Theory: A Framework for Bridging Relational, Multicultural, and Social Justice Competencies. Journal of Counseling \& Development, vol.86:3, pp.279-287.

Dillon, S. (2009). The Missing Link: A Social Orphan Protocol to the United Nations Convention on the Rights of the Child. Administrative \& Regulatory Law News, vol.35, p.7.

Dunn, J. (1988). Relations among Relationships. In S. W. Duck (Ed.), Handbook of Personal Relationships, New York: Wiley, pp.193-209.

Excluded Children. (2010). The Situation of Orphans and Abandoned Children Worldwide. Retrieved from: http://www.soschildrensvillages.org.uk/news/archive/2010/06/ excluded-children-the-situation-of-orphans-and-abandoned-children-worldwide 
Firsava, D. (2012, December). Social Orphans in Belarus: Alcohol Takes Its Toll. Belarus Digest. Retrieved from: http://belarusdigest.com/story/social-orphansbelarus-alcohol-takes-its-toll-12344

Groark, C. J., Muhamedrahimov, R. J., Palmov, O. I., Nikiforova, N. V. \& McCall, R. B. (2005). Improvements in Early Care in Russian Orphanages and their Relationship to Observed Behaviors. Infant Mental Health Journal, vol.26:2, pp.96-109.

Groark, C. J., McCall, R. B. \& Fish, L. (2011). Characteristics of Environments, Caregivers and Children in Three Central American Orphanages. Infant Mental Health Journal, vol.32:2, pp.232-250.

Guqa, V. V. (2012). The Psychological Impact of Caregiving on Carers of HIV/Aids Orphans. (Master's thesis, University of South Africa, Pretoria, South Africa). Retrieved from: https://core.ac.uk/download/pdf/16750791.pdf

Hellenthal, R. L. (2006). The Separate and Combined Effects of Mother, Father and Peer Attachment on Young Asoloscents' Social, Behavioral and Emotional Adjustment. (Master's thesis, the college of arts and sciences, Ohio University, Columbus. $\mathrm{OH}$ ). Retrieved from: http://rave.ohiolink.edu/etdc/view?acc_num=ohiou1149616245

Hlabyago, K. E. \& Ogunbanjo, G. A. (2009). The Experiences of Family Caregivers Concerning their Care of HIV/AIDS Orphans. African Journals Online, vol.51:6, pp.506-511.

Holden, G. W. \& Ritchie, K. L. (1991). Linking Extreme Marital Discord, Child Rearing, and Child Behavior Problems: Evidence from Battered Women. Child Development, vol.62:2, pp.311-327.

Hong, Y., Li, X., Fang, X., Zhao, G., Zhao, J., Zhao, Q. \& Stanton, B. (2011). Care Arrangements of AIDS Orphans and their Relationship with Children's Psychosocial Well-Being in Rural China. Health Policy and Planning, vol.26:2, pp.115-123.

Howard, B. H., Phillips, C. V., Matinhure, N., Goodman, K. J., McCurdy, S. A. \& Johnson, C. A. (2006). Barriers and Incentives to Orphan Care in a Time of AIDS and Economic Crisis: A Cross-Sectional Survey of Caregivers in Rural Zimbabwe. BMC Public Health, vol.6:1, p.27. 
Joint United Nations Programme on HIV/AIDS (2007). Children on the Brink, 2004: A Joint Report of New Orphan Estimates and a Framework for Action. NewYork: United Nations Children's Fund.

Juffer, F. \& Series, W. A. C. (2008). The Effects of Early Social-Emotional and Relationship Experience on the Development of Young Orphanage Children. Monographs of the Society for Research in Child Development, vol.73:3, p.295.

Killian, B. \& Durrheim, K. (2008). Psychological Distress in Orphan, Vulnerable Children and Non-Vulnerable Children in High Prevalence HIV/AIDS Communities. Journal of Psychology in Africa, vol.18:3, pp.421-429.

Landry, S. H., Smith, K. E., Swank, P. R. \& Miller-Loncar, C. L. (2000). Early Maternal and Child Influences on Children's Later Independent Cognitive and Social Functioning. Child Development, vol.71:2, pp.358-375.

Lassi, Z. S., Mehmud, S. \& Syed, E. U. (2010). Behavioral Problems among Children Living in Orphanage Facilities of Karachi, Pakistan: Comparison of Children in an SOS Village with Those in Conventional Orphanages. Social Psychiatry, vol.46:8, pp.787-796.

Lovejoy, M. C., Graczyka, P.A., O'Harea, E. \& Neumana, G. (2000). Maternal Depression and Parenting Behavior: A Meta-Analytic Review. Clinical Psychology Review. vol.20:5, pp.561-592.

Makame, V., Ani, C. \& Grantham-McGregor, S. (2002). Psychological Well-Being of Orphans in Dar El Salaam, Tanzania. Acta Paediatrica, vol.91:4, pp.459-465.

Meadows, S. O., McLanahan, S. S. \& Brooks-Gunn, J. (2007). Parental Depression and Anxiety and Early Childhood Behavior Problems across Family Types. Journal of Marriage and Family, vol.69:5, pp.1162-1177.

Miller, C. M., Gruskin, S., Subramanian, S. V., Rajaraman, D. \& Heymann, J. (2005). Orphan Care in Botswana's Working Households: Growing Responsibilities in the Absence of Adequate Support. American Journal of Public Health, vol.96:8, pp.1429-1435.

Miller, J. B. (1976). Toward a New Psychology of Women. Boston: Beacon Press.

Oburu, P. O. (2005). Caregiving Stress and Adjustment Problems of Kenyan Orphans Raised by Grandmothers. Infant and Child Development, vol.14:2, pp.199-210. 
Radcliff, E., Racine, E. F., Huber, L. R. B. \& Whitaker, B. E. (2012). Association between Family Composition and the Well-Being of Vulnerable Children in Nairobi, Kenya. Maternal and Child Health Journal, vol.16:6, pp.1232-1240.

Rakow, A., Forehand, R., Haker, K., McKee, L. G., Champion, J. E., Potts, J. \& Compas, B. E. (2011). The Association of Parental Depressive Symptoms with Child Internalizing Problems: The Role of Parental Guilt Induction. Journal of Family Psychology: JFP: Journal of the Division of Family Psychology of the American Psychological Association (Division 43), vol.25:1, pp.147-151.

Schonteich, M. (2002). The Coming Wave Crime? AIDS, Orphans and Crime in South Africa: SA J HIV Med :30-4. In Hlabyago, K.E. \& Ogunbanjo, G.A. (2009). The Experiences of Family Caregivers Concerning their Care of HIV/AIDS Orphans. South African Family Practice, vol.51:6, pp.506-511.

Sturge-Apple, M. L., Davies, P. T., Cicchetti, D. \& Manning, L. G. (2012). Interparental Violence, Maternal Emotional Unavailability and Children's Cortisol Functioning in Family Contexts. Developmental Psychology, vol.48:1, pp.237-249.

Sun, S., Li, L., Ji, G., Lin, C. \& Semaan, A. (2008). Child Behaviour and Parenting in HIV/AIDS-Affected Families in China. Vulnerable Children and Youth Studies, vol.3:3, pp.192-202.

Susman, E. J., Trickett, P.K., Iannotti, R. J., Hollenbeck, B.E. \& Zahn-Waxler, C. (1985). Child-Rearing Patterns in Depressed, Abusive and Normal Mothers. American Journal of Orthopsychiatry, vol.55:2, pp.237-251.

Thielman, N., Ostermann, J., Whetten, K., Whetten, R., O'Donnell, K. \& Positive Outcomes for Orphans (POFO) Research Team. (2012). Correlates of Poor Health among Orphans and Abandoned Children in Less Wealthy Countries: The Importance of Caregiver Health. PLoS One, vol.7:6, p.e38109.

UNAIDS (2008). Caregiving in the Context of HIV/AIDS: Joint United Nations Program on HIV. Division for the Advancement of Women. New York: Department of Economic and Social Affairs.

Walker, L. E. (1979). The Battered Woman. New York: Harper \& Row. In Holden, G. W., \& Ritchie, K. L. (1991), Linking Extreme Marital Discord, Child Rearing, and Child Behavior Problems: Evidence from Battered Women. Child Development, vol.62:2, pp.311-327. 
Zhao, Q., Li, X., Fang, X., Zhao, G., Zhao, J., Lin, X. \& Stanton, B. (2010). Difference in Psychosocial Well-Being between Paternal and Maternal AIDS Orphans in Rural China. Journal of the Association of Nurses in AIDS Care, vol.21:4, pp.335-344.

Zhou, G. (2012). Understanding the Psychosocial Well-Being of Orphans and Vulnerable Children (OVC): The Intersection of Research and Policy. (Undergraduate Thesis, Duke University-Durham, Sanford Institute of Public Policy Studies). Retrieved from: http://dukespace.lib.duke.edu/dspace/bitstream/handle/10161/5386/Grace\%20Zho u\%20FINAL.pdf;sequence $=1$

\section{Appendix}

\section{Interview Schedule}

Q.1. Tell something about your own self.

Q.2. Why did you start working in the orphanage?

Q.3. Did you face any challenges while working as caregiver? If yes, could you please share in detail?

Q.4. Q4. How do you deal with such challenges?

Sundus Yousuf is M.Phil Scholar and Internee in the Institute of Clinical Psychology, University of Karachi.

Dr. Bushra Khan is an Assistant Professor in the Department of Psychology, University of Karachi. 